\title{
ENSAIO SOBRE A LITERATURA DE ANÁLISE DOS EFEITOS DA EDUCAÇÃO NO CRESCIMENTO ECONÓMICO
}

\author{
Ana Sofia Domingues Rodrigues*
}

Este ensaio sumariza e analisa as mais importantes contribuições teóricas e empíricas para a avaliação e o entendimento dos efeitos da educação no desempenho dos países em termos de crescimento económico. São abordados dois debates: a controvérsia "primeiras diferenças versus niveis" e o "paradoxo micro-macro".

Neste trabalho são expostas as dificuldades que surgem quando se tenta modelizar os beneficios da educação, assim como a incerteza que rodeia os resultados empíricos. Manifesta-se, no entanto, um claro apoio aos efeitos da educação em termos de produtividade económica e é expressa também a convicção de que os beneficios mais amplos da educação poderão permanecer sempre subestimados.

Palavras Chave: crescimento, desenvolvimento, educação, recursos humanos

This essay summarizes and analyses the most important theoretical and empirical contributions to assess and understand the effects of education on the performance of countries in terms of economic growth. Two debates are approached: the controversial issue "first differences versus levels" as well as "micro-macro paradox".

In this paper are shown the differences that come up when one try to develop models of education benefits, as well as the uncertainty of the empirical results. It is given, however, a clear support to the education effects in terms of economic productiveness and it is also expressed the conviction that the widest benefits of education may be many times underestimated.

Key words: grouth, development, education, human resources

\footnotetext{
${ }^{*}$ Department of Economics and Related Studies, University of York.
} 


\section{INTRODUÇÃO}

"Economists have long known that people are an important part of the wealth of nations. Measured by what labour contributes to output, the productive capacity of human beings is now vastly larger that all other forms of wealth taken together.

And for men to look upon himself as a capital good, even if it did not impar his freedom, may seem to debase him. No less a person than J. S. Mill at one time insisted that the people of a country should not be looked upon as wealth because wealth existed only for the sake of people. But surely Mill was wrong; there is nothing in the concept of human wealth contrary to his idea that it exists only for the advantage of people. By investing in themselves people can enlarge the range of choices available to them. It is one way free man can enhance their welfare."

Theodore Schultz (1961)

A ciência económica desde sempre devotou particular atenção ao estudo dos determinantes do crescimento e desenvolvimento das nações, aquilo que Lucas (1988) designou de o problema do desenvolvimento económico: "explicar os padrões observados, para os vários países e ao longo do tempo, em termos de níveis e taxas de crescimento do rendimento per capita." (Lucas (1988), pp. 3)

A relação entre o desenvolvimento dos recursos humanos e o crescimento económico assumiu sempre particular relevo no contexto da ciência económica, enfatizado nos anos 60 com a human capital investment revolution in economic thought. Refiram-se as contribuições de Theodore Shultz (1961), Gary Becker (1964) e Denison (1967), que deram destaque à importância do capital humano, nomeadamente no crescimento económico. O interesse no retorno ao investimento em capital humano não se confina à literatura macroeconómica. Nos anos 90 , também a microeconomia e a economia do trabalho estudaram este assunto. Esta linha de investigação teve como ponto de partida o modelo de Mincer (1974), mais precisamente, a função Minceriana de rendimentos do capital humano, que identifica o aumento no nível médio de escolaridade como o determinante do aumento do rendimento. Os estudos empíricos no domínio da microeconomia mostram claros indícios de altos retornos ao investimento em capital humano.

Contudo, apesar de a investigação microeconómica e os avanços teóricos na literatura do crescimento económico mostrarem que a educação é um dos principais pilares do desempenho económico de um país, o trabalho empírico nesta área é ainda inconclusivo. As análises empíricas na literatura macroeconómica, cujo objectivo é averiguar se são os stocks de capital humano ou a mudança nesses stocks as variáveis explicativas das taxas de crescimento económico, falharam na tentativa de provar a contribuição significativa da acumulação do capital humano 
para o crescimento económico. Desde Benhabid e Spiegel (1994), alguns estudos empíricos apontam para uma ausência de correlação entre crescimento económico e a evolução do capital humano. Esta controvérsia, ao questionar se existem, de facto, retornos sociais à educação, tem sido motivo de grande curiosidade e preocupação entre investigadores económicos e actores da cena política dadas as suas implicações fundamentais para a orientação das políticas governamentais.

Este ensaio está estruturado em três secções. Na secção 1 analisam-se as conclusões das principais contribuições para a teoria do crescimento económico na última metade do século XX. A secção 2 foca o papel da educação no crescimento económico ao expor duas das mais importantes análises da modelização do capital humano na New Growth Theory. A seç̧ão 3 revê a recente investigação empírica dos efeitos da educação no crescimento económico e o "paradoxo micro-macro", ou seja, a divergência de resultados entre a literatura micro e macroeconómica. A secção 4 conclui.

\section{1 - BREVE REVISÃO DAS PRINCIPAIS CONTRIBUIÇÕES PARA A TEORIA DO CRESCIMENTO ECONÓMICO.}

O crescimento económico é uma preocupação antiga entre os economistas, tendo sido tema de estudo e debate desde Adam Smith. O filósofo de Cambridge, Frank Ramsey, com o seu artigo de 1928 "A mathematical theory of saving", pode ser considerado como o pioneiro da abordagem moderna da teoria do crescimento económico. $\mathrm{O}$ artigo de Ramsey representou um passo adiante na teoria do crescimento económico assim como em muitas outras áreas da teoria económica. Com uma função de utilidade intertemporal, Ramsey, ao tentar responder à questão - qual é a taxa de poupança óptima numa economia? -, mostrou que os agentes económicos tentam "suavizar" o consumo durante a sua vida. O modelo trata uma economia que pode ser entendida como uma economia do tipo "Robinson Crusoe", ou como uma economia cuja população é constante e que é totalmente controlada por um único indivíduo que toma todas as decisões respeitantes às variáveis económicas. Nesta perspectiva, o modelo de Ramsey prima pela simplicidade e, no entanto, explica muitas das variáveis macroeconómicas como as decisões de consumo, poupança e investimento, o progresso tecnológico, o processo de tomada de decisões intertemporais, os ciclos económicos, a taxa de salário real e a taxa de juro. O modelo de Ramsey era analiticamente sofisticado, talvez demasiado para a época. Permaneceu, por isso, ignorado por muito 
tempo. A sua função de utilidade viria a ser adoptada por muitos economistas apenas três décadas após Ramsey a ter proposto.

As contribuições para a teoria do crescimento económico podem agrupar-se em três vagas de interesse distintas. A primeira surgiu na sequência do trabalho de David Harrod (1948) e Ervsey Domar (1947). Ambos procuraram entender que condições permitiriam a uma economia experienciar crescimento no estado estacionário, a uma taxa constante. Harrod e Domar, seguindo caminhos distintos, chegaram à conclusão de que a economia só poderá manter crescimento no estado estacionário quando "a taxa de poupança nacional igualar o produto do rácio capitaloutput e a taxa de crescimento da procura efectiva".

Solow, em 1956, tentou identificar e ultrapassar uma certa inquietude que sentia com a teoria de Harrod e de Domar. A causa do seu desconforto residia nas hipóteses de que os mais importantes ingredientes desta teoria, nomeadamente a taxa de crescimento da força de trabalho, a taxa de poupança e o rácio capital-output, eram constantes, dados adquiridos. Estes poderiam variar ocasionalmente, mas de forma muito esporádica e independente. $\mathrm{O}$ crescimento no estado estacionário, tal como Harrod e Domar o entendiam, era extremamente instável e pequenos desvios seriam ampliados indefinidamente. Segundo esta teoria, o estado estacionário parece algo impossível de atingir e muito menos de manter numa economia. Solow, em 1987, descreve o estado estacionário na teoria de Harrod e Domar como sendo um "milagre" e argumenta que, se assim fosse, "a história das economias capitalistas seria uma alternação de longos períodos de desemprego galopante e longos períodos de escassez de mão-de-obra”. E ironiza, “(...) uma expedição de Marcianos, ao chegar à Terra, tendo lido esta literatura, esperaria encontrar apenas resquícios de um capitalismo que há muito se havia desmoronado". Estas análises de Solow coincidiram no conteúdo e no tempo com as de Swan. O modelo neoclássico de Solow-Swan propunha a acumulação de capital como o principal motor de crescimento económico no curto prazo. Assim sendo, o investimento, ao aumentar a capacidade produtiva, seria crucial ao crescimento económico. Sendo que o investimento é financiado através da poupança, uma economia cuja taxa de poupança está a aumentar permanentemente experienciará crescimento económico. Mas, como o impacto de uma unidade adicional de capital é cada vez menor, esta economia não poderá atingir sempre uma taxa de crescimento mais elevada, sendo que no longo prazo a taxa de crescimento económico é antes determinada pelo progresso tecnológico. As políticas governamentais têm, portanto, efeitos em termos dos níveis de output atingidos na economia, mas não em termos das taxas de crescimento. Uma outra análise que advém desta teoria, e que continua hoje a ser objecto de muita investigação e debate, é a questão da convergência 
condicional. De acordo com este modelo, quanto menor for o nível de output produzido numa economia relativamente ao nível de output no estado estacionário, mais elevada será a taxa de crescimento económico desse país, donde se deveria observar convergência económica entre os países. Este assunto foi tema de muitos trabalhos empíricos que não mostraram a convergência prevista pelo modelo teórico, tendo até, pelo contrário, identificado um certo grau de divergência entre algumas economias.

Os modelos de crescimento Neoclássicos, dos quais o modelo discutido anteriormente é o pioneiro, identificam a acumulação de capital físico como o motor do crescimento económico, menosprezando o papel da acumulação de capital humano, o impacto de novas ideias e de novos conhecimentos. Um outro problema do modelo de Solow-Swan é o facto de deixar por explicar quais os mecanismos geradores de crescimento económico, já que as variáveis explicativas do modelo, como o progresso tecnológico e a taxa de crescimento da população, são variáveis exógenas. Não é, de modo nenhum, realista supor que o progresso tecnológico é exógeno, principalmente quando é identificado como sendo a única fonte de crescimento económico sustentado. Estes modelos não serviam o propósito da análise das experiências reais dos países em termos de crescimento económico, com pressupostos que eram simplesmente contrariados pelos estudos empíricos, como sendo o caso da convergência condicional. Lucas (1988) chamou a atenção para o facto de, em análises empíricas, estes modelos deixarem cerca de $50 \%$ do processo de crescimento económico por explicar.

Uma outra vaga de interesse nos determinantes do crescimento económico, apelidada de New Growth Theory, surgiu na tentativa de colmatar as falhas dos modelos neoclássicos, entusiasmando de novo a comunidade científica. Muitos investigadores, entre eles Romer, Lucas, King e Rebelo, desenvolveram novos modelos nos quais o estado estacionário passa a ser determinado endogenamente no modelo, susceptível de ser afectado por políticas governamentais. A característica mais identificativa destes modelos, que marca a cisão profunda com os modelos precedentes, reside no facto de preconizarem que alterações permanentes nas políticas governamentais que afectam a taxa de investimento de uma economia podem conduzir a alterações permanentes nas taxas de crescimento económico. Os modelos Neoclássicos previam que o impacto das políticas governamentais se faria sentir apenas nos níveis de output produzido numa economia, isto é, em termos de level effects, contrastando profundamente com o impacto nas taxas de crescimento económico, ou growth effects, previsto pelos modelos desta segunda vaga. Estas previsões são comuns aos modelos AK de Romer (1986,1987), Lucas (1988), e Rebelo (1991), assim como aos modelos de 
Romer (1990), Grossman e Helpman (1999 a,b) e Aghion e Howitt (1999), que enfatizam o papel do progresso tecnológico endógeno.

Lucas, em 1988, inspirado nos trabalhos pioneiros de Schultz (1963) e Becker (1964) propôs o capital humano como motor do crescimento em alternativa ao progresso tecnológico. No modelo de Lucas os indivíduos dividem o seu tempo entre duas actividades: adquirir conhecimentos através da escola, aumentando consequentemente o seu nível de capital humano, ou participar no processo de produção de bens e serviços. $\mathrm{O}$ acréscimo de capital humano de um indivíduo não beneficia apenas esse indivíduo mas também a sociedade em geral porque o nível agregado de capital humano na economia contribui para o aumento da produtividade dos outros factores na economia. Neste modelo, os indivíduos não levam em conta o último dos efeitos mencionados, o efeito externo, na tomada de decisões relativas à "quantidade" de educação a adquirir, conduzindo a economia para uma situação de subinvestimento em capital humano. Este modelo aproximou a teoria económica dos resultados empíricos no que concerne à questão da convergência condicional, ao prever que o estado estacionário para onde tende uma economia depende, em grande medida, das condições de partida para essa economia. Assim sendo, existe não um, mas antes uma multiplicidade de estados estacionários, e um país que é inicialmente pobre assim o permanecerá, mesmo que tenha uma taxa de crescimento económico igual à de um país inicialmente rico.

No modelo de Romer (1990), o capital humano é um determinante da oferta de novas ideias e novas tecnologias, introduzindo a importância da criatividade. $\mathrm{O}$ investimento em capital humano é fundamental, neste modelo, ao permitir inovação ou progresso ao nível da utilização de capital físico que, por sua vez, influenciará a taxa de crescimento económico. Romer argumenta que o capital humano é um determinante da taxa de crescimento económico dos países desenvolvidos e subdesenvolvidos devido ao seu efeito no capital físico.

Os modelos de crescimento endógeno representam um passo em frente em relação aos modelos que os precederam, ao modelizar o crescimento económico de uma forma endógena, ao introduzirem a importância das externalidades positivas do conhecimento e da criação de ideias, e ao fazer o fluxo destes factores depender da quantidade de recursos afectos à sua produção. Mas estes modelos não são, naturalmente, perfeitos. Lucas e Romer referem a capacidade dos indivíduos de transmitirem a sua "riqueza" em capital humano às gerações seguintes. No entanto, o capital humano na perspectiva das qualificações de um indivíduo para fazer algo, esgota-se no próprio indivíduo, tem a sua finitude na finitude do próprio indivíduo e não se perpetua. Já o stock de conhecimentos de uma economia é susceptível de tranferência inter-gerações. Consequentemente, será o stock de 
conhecimentos que pode crescer ilimitadamente e que estará na origem do crescimento económico. Uma outra imperfeição destes modelos de crescimento económico está associada a uma das hipóteses de partida do modelo: a hipótese de retornos constantes à escala. Esta restrição é redutora uma vez que um pequeno desvio desta hipótese implicaria um estado estacionário no qual não há crescimento das variáveis per capita. Ainda assim, estes modelos de crescimento representam, indubitavelmente, um enorme progresso na teoria do crescimento económico, porque explicam o crescimento económico contínuo, as diferenças nas taxas de crescimento de longo prazo para os diferentes países e permitem prever os resultados das políticas governamentais susceptíveis de alterar o rácio capital-trabalho.

Um grupo de investigadores do MIT, seguidores de Robert Solow, desafiaram todo o entusiasmo com os modelos de crescimento endógeno, dando origem ao que viria a ser designado de Cambridge Counter-revolution. Mankiw, Romer e Weil (1992) levaram Robert Solow muito a "sério", como eles próprios afirmam, ao desenvolver uma reconstrução do modelo de Solow com o acréscimo do capital humano, que "roubam" à literatura do crescimento endógeno. Mankiw, Romer e Weil argumentam que as mais importantes previsões do modelo de Solow- um país é tanto mais rico quanto mais elevada a sua taxa de poupança e mais baixa a taxa de crescimento da sua população- estão de acordo com os dados estatísticos, e que este modelo é muito mais poderoso e tem muito mais verificação empírica do que o que é sugerido pelos seguidores da teoria do crescimento endógeno. Utilizando observações para um grande número de países, Mankiw et al (1992) mostram que a taxa de poupança e a taxa de crescimento da população afectam o rendimento na direcção prevista por Solow, mas mostram também que apesar da direcção desses efeitos estar correctamente prevista, as magnitudes não o estão. $\mathrm{O}$ impacto do crescimento da poupança e da população estimado pelo modelo de Solow tal como proposto por Mankiw et al é muito superior àquele previsto pelo modelo original. Os autores concluem que o modelo de Solow, na sua versão original, não era totalmente bem sucedido, mas era, no entanto, um modelo com um bom desempenho empírico e que sugere uma importante informação para toda a teoria do crescimento económico: variáveis facilmente observáveis explicam uma parte muito significativa da variação no rendimento. Com o intuito de melhorar o desempenho do modelo de Solow, Mankiw, Romer e Weil aperfeiçoamno ao introduzir uma segunda forma de capital- o capital humano. Utilizando uma proxi para a acumulação de capital humano nas suas regressões, observam que este está altamente correlacionado com o crescimento da população e da poupança. No modelo de Mankiw, Romer e Weil, a função de produção assume a seguinte forma: $Y_{t}=K_{t}^{\alpha} H_{t}^{\beta}\left(A_{t}\right.$ 
$\left.L_{t}\right)^{1-\alpha-\beta}$, onde $H_{t}, K_{t}, A_{t}$ e $L_{t}$ representam, respectivamente, o stock de capital humano, capital físico, a tecnologia e a força de trabalho no momento $t$. Definindo $s_{k}$ e $s_{h}$ como as fracções constantes do rendimento investido em capital físico e capital humano, a evolução da economia pode ser resumida através das duas equações seguintes:

$$
\left\{\begin{array}{l}
\dot{k}_{t}=s_{k} y_{t}-(n+g+\delta) k_{t} \\
\dot{h}_{t}=s_{h} y_{t}-(n+g+\delta) h_{t}
\end{array}\right.
$$

onde $k_{t}, h_{t}$ e $y_{t}$ representam, respectivamente, o capital físico, o capital humano e o rendimento, em unidades de eficiência. É assumida a mesma taxa de depreciação $\delta$ para o capital humano e o capital físico. Este modelo tem um excelente desempenho empírico, explicando cerca de $80 \%$ da variação do rendimento entre países e proporciona uma resposta bastante completa para a questão fundamental na teoria do crescimento económico: porque é que alguns países são tão pobres e outros tão ricos. Esta era, de facto, a questão a que Solow se propunha responder, e estes seus seguidores argumentam que Solow atingiu os seus propósitos. Mankiw, Romer e Weil concluem que "o modelo de Solow é consistente com as diferenças internacionais ao tomarmos em consideração a importância do capital humano, assim como a do capital físico" (Mankiw et al (1992), PP 433). Este apoio aos modelos Neoclássicos foi fortalecido pela contribuição de Charles Jones (1995a e 1995b). Jones argumenta que a mais importante implicação dos modelos de crescimento endógeno, que enfatiza a importância dos recursos afectos à $I \& D$ como determinante da taxa de crescimento de longo prazo, não tem verificação empírica. Jones testa esta previsão ao comparar o investimento como uma fracção do PIB e a taxa de crescimento do PIB para uma amostra de 15 países da OCDE, utilizando observações para o período pós Segunda Guerra Mundial. Este autor chama a atenção para o facto de as taxas de investimento terem vindo a crescer, enquanto que as taxas de crescimento do PIB se mantiveram constantes, ou decresceram. Jones critica também os modelos de acumulação de conhecimento, argumentando que este tipo de modelos ignora o facto de a criação de conhecimento se tornar cada vez mais morosa e difícil à medida que o tempo passa, já que as ideias mais "fáceis" são as primeiras a ser descobertas e, consequentemente, com a passagem do tempo, os investigadores vêem-se a mãos com áreas cada vez mais exploradas. 


\section{2 - MODELIZAÇÃO DOS EFEITOS DA EDUCAÇÃO NO CRESCIMENTO ECONÓMICO}

Os modelos de crescimento endógeno apresentados na secção anterior constituem uma boa estrutura para analisar a importância da educação como um factor determinante da taxa de crescimento de longo prazo. Aghion e Howitt (1998) distinguem dois grupos de análise na relação entre educação e crescimento económico. O primeiro, proposto por Lucas (1988), baseado na teoria Beckeriana do capital humano (1964), identifica a acumulação de capital humano como o principal motor do crescimento económico. Segundo esta abordagem, as diferenças entre as taxas de acumulação de capital humano entre os países podem ser vistas como a principal causa das diferenças entre as taxas de crescimento económico. O segundo grupo de análise é o de Nelson e Phelps (1966) e tem sido recentemente revisto pela teoria Schumpeteriana. De acordo com esta corrente, o principal motor do crescimento económico é o stock de capital humano ao afectar a capacidade de um país de gerar progresso tecnológico assim como a de adoptar tecnologias produzidas no estrangeiro.

Lucas (1988) considera uma economia fechada e uma função de produção neoclássica standard, em que indivíduos idênticos decidem, em cada período da sua vida, quanto tempo devem dedicar à educação para aumentar os seus níveis de produtividade e de capital humano que elevarão, consequentemente, o seu salário futuro, e quanto tempo devem trabalhar. O efeito do capital humano no output é captado na seguinte função de produção:

$$
y_{t}=k_{t}^{\beta}\left(u_{t} h_{t}\right)^{1-\beta}
$$

em que $h_{t}$ representa o stock de capital humano per capita no período $t$, e $u_{t}$ designa a fracção de tempo dedicada à produção no período $t$. Neste quadro, a evolução do capital físico é dada pela diferença entre o que é produzido e o que é consumido na economia num dado período, enquanto que a evolução do capital humano é dada por:

$$
\dot{h}_{t}=\Psi h_{t}\left(1-u_{t}\right) \Psi>0
$$

em que $\Psi$ representa a produtividade da educação. Esta equação transmite a ideia de que quanto maior for o tempo dedicado à educação $\left(1-u_{t}\right)$, maior será a acumulação de capital humano. A análise de Lucas permite ainda uma generalização que capta a ideia da existirem externalidades entre trabalhadores: 


$$
y_{t}=k_{t}^{\beta}\left(u_{t} h_{t}\right)^{1-\beta}\left(\bar{h}_{t}\right)^{\gamma}
$$

em que $\bar{h}$ representa o nível médio de qualificações ou efeito externo, uma vez que este tem externalidades positivas na produtividade dos restantes factores da economia.

No modelo de Lucas, a taxa de crescimento no estado estacionário, $\mathrm{g}$, é positiva e é maior quanto maior for a fracção de tempo afecta à educação: $g=\Psi\left(1-u^{*}\right)$, onde $\mathrm{u}^{*}$ constitui a afectação óptima entre educação e produção, isto é, aquela que maximiza a utilidade intertemporal do consumidor representativo sujeita à função de produção e às equações que representam a moção do capital físico e do capital humano. De acordo com este modelo, um crescimento sustentável é apenas possível se o capital humano puder crescer sem restrições. No entanto, esta análise é incompatível com a concepção de capital humano em termos de educação adquirida, tais como os anos de escolaridade. $\mathrm{O}$ conceito de capital humano no modelo de Lucas parece estar mais relacionado com o conhecimento do que propriamente com medidas quantitativas de escolaridade.

O modelo simplificado de Lucas foi alvo de extensões várias. Rebelo (1991) modeliza uma economia na qual não existem externalidades e onde o capital físico é usado na produção de capital humano. Rebelo mostra que, neste modelo, não é necessário assumir nem retornos crescentes, nem externalidades, para que haja crescimento endógeno. Este novo cenário permite-lhe analisar os efeitos da aplicação de impostos, como a taxa do imposto sobre o rendimento, na taxa de crescimento e, consequentemente, concluir acerca do impacto das políticas fiscais que afectam a acumulação de capital humano através do seu efeito no capital físico. O objectivo de Rebelo é mostrar que as diferenças de rendimento entre países podem ser resultado das diferenças entre as políticas governamentais de cada país. Contudo, estes modelos baseados na perspectiva de Lucas tomam os retornos ao investimento em capital humano como constantes ao longo da vida de um indivíduo, enquanto a abordagem Beckeriana do capital humano considera que os retornos ao investimento em capital humano são decrescentes ao longo da vida de um indivíduo, uma ideia claramente mais realista.

Para Nelson e Phelps, o capital humano não é visto apenas como um simples input na função de produção, mas sim como a principal fonte de inovação. Nelson e Phelps salientam o papel da educação no aumento da capacidade de inovação bem como da capacidade de adaptação a novas tecnologias. Desta forma, a taxa de crescimento depende da taxa de inovação e, consequentemente, do nível de capital humano e não da sua taxa de crescimento como era o caso nos modelos Lucasianos. Esta 
abordagem sugere uma complementaridade entre educação e I\&D que implica que as políticas educacionais devem ser acompanhadas de incentivos a actividades de I\&D, uma vez que são estas actividades que vão aumentar a procura de trabalhadores qualificados. Por outro lado, as políticas educacionais destinadas a melhorar ou subsidiar a oferta de investigadores levam, por sua vez, ao aumento do retorno a actividades de I\&D. A complementaridade entre políticas de educação e I\&D tem um papel vital ao evitar que uma economia caia numa "armadilha de baixa qualificação, baixa qualidade". O termo "armadilha" traduz a ideia do círculo vicioso que pode surgir no caso de haver uma situação de falha de coordenação na qual os indivíduos não investem em educação porque pensam que as empresas não vão tirar partido desse investimento e estas não seguem um processo inovador por entenderem que a força de trabalho não é suficientemente qualificada para tirar partido de novas descobertas. Romer (2000) salienta a importância desta complementaridade ao analisar as razões que levaram ao insucesso das políticas de fomento da inovação levadas a cabo nos EUA nas últimas duas décadas. Segundo Romer, apesar da avultada despesa associada a estas políticas, que tinham como propósito último o aumento da taxa de progresso tecnológico, os programas governamentais falharam ao menosprezar a estrutura das instituições de ensino superior. Na sua análise, Romer chama a atenção para o facto de o crescimento económico ser determinado pela quantidade de inputs em I\&D e não apenas pela despesa nestes. Segundo Nelson e Phelps, as políticas de educação têm um importante papel em economias menos avançadas tecnologicamente uma vez que são essas políticas que aumentam a capacidade de um país de adoptar inovações produzidas exteriormente. Este raciocínio é, na verdade, a formalização da hipótese de catch-up originalmente proposta pelo historiador económico de Harvard, Gerschenkron (1952).

Estas duas principais correntes de modelização do capital humano parecem ser bastante divergentes e implicam diferentes formas de introduzir o capital humano em regressões do crescimento económico, dando origem à controvérsia "primeiras diferenças versus níveis". Aghion e Howitt (1998) chamaram a atenção para o facto de esta controvérsia poder, muito simplesmente, não ser controvérsia nenhuma! De facto, estas duas formas de abordagem do capital humano podem ser consideradas diferentes pelo simples facto de se referirem a formas distintas de capital humano. Este pode ser encarado como qualquer outro input na função de produção, tal como postulado por Lucas, se nos estivermos a referir ao stock de capital humano de uma economia associado a mais baixos níveis de qualificações. Por outro lado, se nos estivermos a referir ao stock de capital humano altamente qualificado, que constitui um importante determinante dos avanços tecnológicos e 
inovação, então a forma como Nelson e Phelps encaram o capital humano revela-se mais apropriada.

\section{3 - RESULTADOS EMPÍRICOS NO QUE CONCERNE OS EFEITOS DA EDUCAÇÃO NO CRESCIMENTO ECONÓMICO.}

Grande parte da investigação dedicada à educação e à sua relação com o crescimento económico tem sido desenvolvida no domínio empírico. $\mathrm{O}$ trabalho empírico na área da macroeconomia sobre este assunto tenta medir os benefícios da educação para a produtividade económica, com base nos níveis de educação dos diferentes países e nas suas taxas de crescimento económico. Mas, enquanto que no domínio teórico a educação é tida como um importante determinante das taxas de crescimento de longo prazo, os resultados empíricos são inconclusivos. Os estudos microeconométricos baseados na função minceriana fornecem dados consistentes com a ideia de retornos substanciais ao investimento em capital humano. No entanto, as regressões do crescimento económico não produziram resultados concludentes, sugerindo que os retornos ao investimento em educação ficam aquém das previsões fornecidas pela literatura microeconómica. Estes resultados são ainda mais surpreendentes se considerarmos que a existência de externalidades positivas na educação faria antever uma superioridade dos retornos sociais previstos pela literatura macroeconómica relativamente aos retornos privados previstos pela literatura microeconómica. Mais inesperado, ainda, é o facto de alguns estudos recentes não terem encontrado nenhuma correlação entre a taxa de crescimento económico e a evolução do capital humano. Esta divergência entre resultados micro e macroeconómicos, referida como o "paradoxo micro-macro", tem vindo a concentrar atenções na investigação económica e assume particular relevância na análise dos retornos aos enormes investimentos em educação concretizados desde a Segunda Guerra Mundial. No que respeita a este paradoxo, discutiremos aquelas que consideramos serem as três gerações de estudos mais importantes. As primeiras análises empíricas neste assunto foram levadas a cabo por Barro (1991) e Mankiw, Romer e Weil (1992). Os autores estimam o impacto das variações nas taxas de ingresso escolar na taxa de crescimento do PIB (real) utilizando dados relativos a países industrializados assim como a países subdesenvolvidos, e concluem a favor de um impacto positivo substancial do nível de instrução de um país na sua taxa de crescimento económico. No entanto, esta análise pode ser distorcida pela inclusão de países de tão diferentes graus de desenvolvimento na amostra pois não parece sensato concluir acerca dos efeitos da educação para o crescimento 
económico dos países industrializados com base em resultados que podem ser dominados pela presença de países subdesenvolvidos na amostra. Bassanini e Scarpetta (2002) estimam uma função de crescimento económico, no contexto do modelo de Solow, tal como é proposto por Mankiw, Romer e Weil (1992), utilizando "Pooled mean group estimators" que permitem variações nos coeficientes de curto prazo para os diferentes países, para estimar o parâmetro que capta a relação de longo prazo entre o crescimento económico e a evolução do capital humano. Os resultados estão muito próximos dos valores previstos para os retornos privados que provêm dos estudos microeconométricos, fazendo prever externalidades muito pequenas na educação. Os resultados de Barro e Sala-i-Martin (1995) também se mostram favoráveis à ideia do impacto positivo da educação. Esta primeira vaga de estudos vem confirmar as expectativas do domínio teórico de um impacto positivo da educação no crescimento económico, analisadas na secção 1 .

Uma segunda geração de estudos produziu resultados muito distintos: não encontraram correlação alguma entre a taxa de crescimento do capital humano e a taxa de crescimento económico. Lau, Jaminson, e Louat (1991) estimaram os efeitos da educação no crescimento económico para cinco regiões, sendo que os parâmetros estimados para a África, o Médio Oriente e Norte de África assumiram valores negativos, e se revelaram insignificativos para os países do sul do continente asiático e da América Latina. Até mesmo o relatório do Banco Mundial de 1995, que tanto argumenta a favor de políticas de fomento à educação, mostra resultados de uma relação ténue entre o crescimento do nível de instrução e o crescimento económico. Os resultados de Benhabib e Spiegel (1994), Islam (1995) e Caselli, Equivel e Leffort (1996) são consistentes com os do estudo supracitado ao mostrar uma ausência de correlação entre as taxas de crescimento do capital humano e a taxa de crescimento económico. Entre estes, o contributo de Benhabib e Spiegel assume particular importância ao utilizar uma forma mais rica de modelização do impacto do capital humano no crescimento económico que se baseia na abordagem de Nelson e Phelps. Benhabib e Spiegel estimam uma função muito semelhante à proposta por Mankiw, Romer e Weil (1992), mas abandonam as hipóteses de estado estacionário dos seus antecessores. Os autores descobrem que, neste contexto, o crescimento do capital humano não tem qualquer poder explicativo do crescimento do output. Propõem, então, um modelo alternativo que realça a importância do stock de capital humano na determinação da capacidade de um país de inovar e da capacidade de adopção de novas tecnologias produzidas no exterior, isto é, influenciando a velocidade a que se dá o catch up tecnológico. Enquanto que para Mankiw, Romer e Weil o capital humano entra na função de produção como um input directo, Benhabib e Spiegel assumem 
uma função de produção onde o capital humano actua como input indirecto através do termo da produtividade total dos factores, que pode ser representada da seguinte forma: $Y_{t}=A_{t}\left(H_{t}\right) K_{t}^{\alpha} L_{t}^{\beta}$. Neste modelo, o crescimento do termo de produtividade, $A_{t}$, depende do nível de capital humano através do efeito da inovação e da combinação do nível de capital humano e do fosso tecnológico em relação ao país com a liderança tecnológica (designado, de ora em diante, país líder). Esta abordagem formaliza, de modo mais completo, os mecanismos através dos quais o capital humano afecta o crescimento económico. Os autores estimam o efeito de catch up tecnológico e de inovação interna, utilizando uma formulação que pode ser representada da seguinte forma:

(crescimento da produtividade total dos factores) ${ }_{i}=c+\alpha H_{i}+\beta H_{i} f\left(p_{i}\right)$ $+\theta$ (acumulação de capital físico) ${ }_{i}+\lambda$ (crescimento da força de

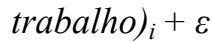

onde o índice $i$ representa o país, c representa o progresso tecnológico exógeno, $H_{i}$ é o nível médio de anos de instrução e $p r_{i} \mathrm{o}$ rácio de produtividade do país líder relativamente ao país $i$. O parâmetro $\alpha$ capta $o$ impacto da educação no progresso tecnológico endógeno associado à capacidade de inovação interna e $\beta$ reflecte o impacto da educação na absorção de tecnologias desenvolvidas no país líder, ou seja, o impacto da educação na produtividade dos factores que advém do catch up tecnológico. Benhabib e Spiegel estimam o modelo para a amostra completa, e depois de dividir esta amostra em três partes, nomeadamente a dos países mais ricos, medianos e mais pobres, estimam o modelo para cada uma delas. Esta divisão da amostra inicial tem o propósito de analisar as diferentes vias através das quais o capital humano afecta o crescimento económico em países desenvolvidos e subdesenvolvidos. Benhabib e Spiegel constatam que, para a amostra dos países mais pobres, o valor estimado para o parâmetro correspondente ao catch up tecnológico é estatisticamente significativo e o estimado para o parâmetro que reflecte a inovação doméstica assume um valor negativo. Os resultados são opostos quando o modelo é estimado utilizando observações dos países mais ricos, onde valor estimado para o parâmetro associado ao efeito de catch up se torna insignificativo e próximo de zero. Já o valor estimado para o parâmetro associado à inovação doméstica é agora positivo e estatisticamente relevante. De forma a silenciar argumentos de que os seus resultados para o termo de catch up advêm do efeito de convergência neoclássico, os autores mostram que os seus resultados são robustos à introdução do rendimento inicial no modelo. No que concerne a importância da acumulação de capital humano para o crescimento económico, o trabalho de Benhabib e Spiegel mostra que o 
valor estimado para o parâmetro associado ao crescimento do capital humano se revela negativo e insificativo. Estes resultados vão ao encontro da abordagem de Nelson e Phelps, uma das formas de modelização dos efeitos da educação no crescimento económico tratadas na secção 2 , que prevê um impacto positivo do stock de capital humano no crescimento económico, mas não da sua taxa de crescimento.

Uma terceira vaga de estudos propôs um conjunto de explicações plausíveis para os resultados que mostram uma ausência de correlação, ou mesmo uma correlação negativa, entre a acumulação de capital humano e o crescimento económico. Pritchett, no seu artigo de 1999 "Where has all the education gone?", propõe um conjunto de três possíveis justificações para o ténue ou inexistente impacto no crescimento económico dos investimentos massivos em educação desde os anos 60, mais conhecido como a "hipótese de Pritchett". Segundo Pritchett, o impacto dos investimentos em educação difere entre países devido, por exemplo, aos diferentes contextos institucionais específicos de cada país onde se experiencia o crescimento na educação. Estas particularidades institucionais dos países podem fazer com que aumentos da escolaridade média da força de trabalho não tenham qualquer impacto no desempenho económico de um país. Se o ambiente institucional de um país for suficientemente perverso, poderá mesmo registar-se um impacto negativo. Este será o caso se o novo conhecimento criado for orientado para actividades remunerativas do ponto de vista privado, mas socialmente improdutivas. Pritchett afirma que o aumento no nível de escolaridade poderá gerar apenas "piratas mais instruídos" que não trazem qualquer tipo de benefício em termos de crescimento económico. Uma outra explicação proposta por Pritchett tem por base as diferenças, entre países, nas taxas de crescimento da procura de força de trabalho instruída, já que países com o mesmo nível de retorno ao investimento em educação podem ver os retornos marginais à educação diminuir drasticamente, manterem-se ou aumentar. Assim sendo, a evidência de um impacto negativo pode ficar a dever-se à diminuição dos retornos marginais à educação que acompanha um aumento na oferta de trabalhadores intruídos não correspondida por um aumento equivalente na procura desta força de trabalho. A terceira razão proposta tem a ver com a qualidade da educação. Pritchett argumenta que em alguns países, principalmente países subdesenvolvidos, a transmissão de conhecimentos e qualificações nas instituições de educação é tão pequena que poderá não ter efeito algum no capital humano do país em causa.

Jonathan Temple (1999) defende as conclusões da primeira geração de estudos empíricos, argumentando que a correlação entre educação e crescimento económico pode ser deturpada por alguns países da amostra utilizada que são pouco representativos da realidade. Este é o risco que 
emerge de introduzir observações de países muito heterogéneos na amostra utilizada. Temple testa a validade do seu argumento ao aplicar um outro método de estimação, que identifica e elimina as observações com resíduos maiores, ao conjunto de observações utilizado por Benhabib e Spiegel e verifica que o valor estimado do impacto de uma alteração do logaritmo do nível médio de anos de escolaridade é três vezes superior ao estimado por Benhabib e Spiegel.

Uma outra linha de estudos dentro desta terceira geração identifica erros de medição e alterações na qualidade da educação não identificadas como estando na origem dos resultados que mostraram ausência de correlação, contrariamente às previsões das análises teóricas. Krueger e Lindahl (2001), por exemplo, mostram que os resultados são bem diferentes, nomeadamente que o impacto da educação no crescimento económico é positivo e superior ao previsto pelos estudos microeconométricos, uma vez ultrapassado o erro de medição.

A maior parte dos trabalhos empíricos descritos até aqui fazem uso de medidas quantitativas de escolaridade como proxi para o capital humano, ignorando, por completo, a relevância da qualidade da educação e assumindo que variações na qualidade da transmissão de conhecimentos e qualificações são insignificantes comparativamente às variações na sua quantidade. Behrman e Birdsall (1987), e Hanushek e Kimko (2000), entre outros, chamam a atenção para a desadequação deste tipo de medidas do capital humano. A literatura nesta área tem, aliás, atribuído particular atenção à importância de medidas de educação de carácter qualitativo, já que medidas quantitativas da educação como sendo o valor da despesa em educação ou o nível médio de anos de escolaridade, apesar de muito "convenientes", se têm mostrado manifestamente insuficientes para a análise da natureza e da extensão do impacto da educação no crescimento económico. Este conjunto de estudos argumenta que será a forma como a despesa é afecta à educação, e não o montante envolvido, a ter um impacto significativo nas taxas de crescimento económico. Hanushek (1996) faz uma análise interessante das implicações para considerações relativas a política económica destes resultados, realçando que o esforço governamental de fomento da educação não deve ser avaliado pelo montante de despesa por aluno. $\mathrm{O}$ autor afirma que esta medida está pouco relacionada com o desempenho do aluno e que políticas para o fomento da educação centradas no montante de despesa representam um grave equívoco, já que podem resultar em puros despesismos ineficientes na tarefa de aumentar o nível de capital humano de um país. Por outro lado, a medição da qualidade da educação é difícil e tem gerado contervérsia. Hanushek e Kimko (2000) argumentam que as medidas qualitativas da educação mais usuais, como o rácio professor/aluno ou o tamanho da turma, estão pouco relacionadas com o 
desempenho dos alunos e serão, por isso, pobres medidas da qualidade da educação. Propõem, então, medidas qualitativas da educação relacionadas com os níveis cognitivos atingidos. Os autores usam resultados de testes comparativos de matemática e ciências como medida do nível de instrução da força de trabalho e concluem que este último tem um efeito substancial no crescimento económico. A relevância das matérias leccionadas e a formação dos professores são realçadas por Hallack (2000) como importantes determinantes da qualidade da educação.

Após uma breve revisão de alguns trabalhos empíricos conduzidos nesta matéria, fica a ideia de que com o aperfeiçoamento dos metodos de estimação e a utilização de medidas qualitativas da educação, os resultados da literatura empírica aproximar-se-ão, porventura, das previsões do domínio teórico, confirmando a expectativa inicial de um impacto positivo da educação no crescimento económico. Apesar do vasto intervalo de variação dos resultados das análises realizadas, que ora atestam a favor dos efeitos altamente positivos do crescimento da educação no crescimento económico, ora questionam por completo a existência desses efeitos, a dinâmica dos resultados parece deixar antever a solução deste paradoxo.

A discussão em torno dos controversos resultados empíricos da macroeconomia, no que concerne a este assunto, levou a um aprofundamento do conhecimento dos efeitos da educação no crescimento económico e da forma como se processam, com fortes implicações para a análise de políticas educacionais.

\section{CONCLUSÃO}

A modelização das experiências de crescimento económico dos diferentes países, com particularidades tão distintas, levanta muitos problemas, principalmente quando a qualidade da informação utilizada é dúbia e rodeia os trabalhos empíricos de incerteza e cepticismo. Enquanto a literatura microeconómica apresenta resultados consistentes com retornos positivos ao investimento em educação, conquanto a confiança nestes resultados seja algo afectada pela hipótese de serem gerados pelo efeito sinalizador do nível de instrução do indivíduo, os resultados da macroeconomia permanecem algo inconclusivos. Ainda assim, os estudos mais recentes parecem gerar resultados mais consistentes com os da microeconomia, mas o processo de reconciliação destas duas linhas de investigação distintas está, ainda, nos seus inícios.

A contribuição fundamental dos estudos empíricos no contexto dos modelos macroeconómicos assenta no facto de estes permitirem, pelos menos hipoteticamente, testar os efeitos da educação em termos de 
produtividade económica, enquanto que a investigação na área da microeconomia apenas poderá analisar os retornos privados ao investimento em educação, não levando em conta as externalidades da educação e menosprezando, portanto, os seus benefícios mais amplos. A importância dos estudos macroeconómicos é evidente, não obstante os seus resultados serem menos robustos e fiáveis que os da microeconomia.

No campo teórico, é importante referir que, apesar de se estarem a desenvolver formas mais ricas de modelizar os efeitos do capital humano no crescimento económico, estas formulações parecem restringir-se a categorias particulares de resultados, não abrangendo todas as formas através das quais o capital humano afecta o crescimento económico.

Em nosso entender, os amplos benefícios da educação permanecem subestimados, mesmo que não possamos negar a eventualidade de sobre-educação em algumas situações. Porém, parece-nos limitado restringir os efeitos da educação aos seus efeitos na produtividade económica e, mesmo que a sobre-educação seja uma realidade, ela ficar-se-á a dever, na nossa perspectiva, à ausência de incentivos complementares às políticas de fomento da educação. Parece-nos tão fundamental criar qualificações como estimular o seu aproveitamento.

\section{REFERÊNCIAS}

Acemoglu, D. (1996). “A Microfoundation for social increasing returns in human capital accumulation". Quarterly Journal of Economics 111(3): 779-804

Aghion, P. and Howitt, P. (1998). Endogenous growth theory. MIT Press Cambridge

Barro, R.J. (1991). "Economic growth in a cross-section of countries". Quarterly Journal of Economics, 106(2), 407-443.

Barro, R.J. and Lee, J.-W.(1993). "International comparisons of educational attainment". Journal of Monetary Economics, 32, 363-394.

Barro, R.J. and Sala-I-martin,X.(1995).Economic growth. McGraw-Hill, New York.

Bassanini,A. and Scarpetta, S.(2002). "Does human capital matter for growth in the OECD countries? Evidence from pooled mean-group estimates". OECD Economics Department working paper no. 282.

Becker,G.(1964). Human capital. New York: Columbia University Press.

Behrman,J. and Birdsall N. (1987). "The Quality of Schooling: Quantity Alone is Misleading”. American Economic Review, 73(4), 928-946.

Benhabib, J. and Spiegel,M.M.(1994). "The role of human capital in economic development: evidence from aggregate cross-country data". Journal of monetary Economics, 34(2), 143-173.

Bils, M., Klenow, P.J.(2000). "Does schooling cause growth?”. American Economic Review, 90(5), 1160-1183.

Cannon,E.(2000). "Human capital: level versus growth effects". Oxford Economic Papers, 52, 670-676. 
Caselli , F., Equivel , G., Leffort, F (1996) "Reopening the convergence debate: a new look at cross-country growth empirics". Journal of Economic Growth 1, 363389.

Domar, E. (1946) "Capital expansion, rate of growth and unemployment". Econometrica, 14 (2), 137-147.

Denison, E. (1967) "Why growth rates differ: post-war experiences in nine western countries". Washington, D.C.: Brookings Institution.

Gerschenkron, A. (1952). Economic Backwardness in Historical Perspective. B. F. Hoselitz (ed.) The Progress of Underdeveloped Areas. Chicago: University of Chicago Press.

Grossman, G.M., Helpman, E.(1994). "Endogenous innovation in the theory of growth". Journal of Economic Prespectives, 8, 23-44.

Hallack,J.(2000). "Education:Quality counts too". OECD Observer.

Hanushek, E.A., Kimko, D. (2000). "Schooling, labour fource quality, and the growth of nations". American Economic Review, 90 (5), 1184-1208.

Harrod,R. (1948) “Towards dynamic economics”, Macmillan, lecture 3.

Islam, N. (1995). "Growth Empirics: A panel data approach". Quarterly Journal of Economics 110(4): 1127-1170.

Jones,C.I.(1995a). "R\&D-based models of economic growth". Journal of Political Economy, 103, 759-784.

Jones,C.I.(1995b). "Time-series tests of endogenous growth models". Quarterly Journal of Economics 110, 495-525.

Jones,C.I.(1998). Introduction to economic growth. Norton, New York.

King, R.G., Rebelo, S. (1990). "Public policy and economic growth: developing neoclassical implications". Journal of Political Economy, 98, S126-S150.

Krueger,A.B. and Lindahl, M.(1999). "Education for growth in Sweden and the world". NBER working paper no. 7190.

Krueger,A.B. and Lindahl, M.(2001). "Education for growth: Why and for whom?". Journal of economic literature, 39, 1101-1136.

Lau, L., Jaminson, D., Louat, L. (1991). “Impact of education by region”, World Bank, Washinton, D.C. Processed.

Lucas,R.E.(1988). "On the mechanisms of economic development". Journal of Monetary economics, 22 ,3-42.

Mankiw, N.G., Romer,D. and Weil,D. (1992). "A contribution to the empirics of economic growth". Quarterly Journal of Economics, 107, 407-437.

Mincer, J.(1974). Schooling, experience and earnings. Columbia University Press.

Nelson, R., Phelps,E. (1996). "Investment in humans, technological diffusion and economic growth". American Economic Review 61, 69-75.

Pritchett, L. (1996). "Where has all the education gone?". World Bank Policy Research Department working paper no. 1581.

Ramsey, F. (1928). “A mathematical theory of saving”. Economic Journal 38, 543559.

Rebelo,S.(1991). "Long-run policy analysis and long-run growth". Journal of Political Economy, 99, 500-521.

Romer, P.M. (1986), "Increasing returns and long-run growth", Journal of Political Economy, 94, 1002-1037.

Romer, P.M. (1987), "Growth based on increasing returns due to specialization", American Economic Review, 77, 56-62.

Romer, P.M. (1990a). "Endogenous technological change". Journal of Political Economy, 98(5), S71-S102. 
Romer, P.M. (1990b). "Human capital and growth: theory and evidence". Carnegie Rochester conference series on Public Policy, 32, 251-286.

Romer, P.M. (2000). "Should Governments subsidize supply or demand in the markets for scientists and engineers?". NBER working paper no. 7723.

Rustichini, A. and Schmitz, J.A.(1991). "Research and imitation in long-run growth". Journal of Monetary Economics, 27(2), 271-292.

Scarpetta, S., Bassanini, A., Pilat, D. and Schreyer, P. (2000). "Economic growth in the OECD area: recent trends at the aggregate and sectoral level". OECD Economics Department working paper no 248.

Schultz, T. (1961) "Investment in Human Capital" American Economic Review, March 1961, 1- 17.

Solow, R.M. (1957). "Technical change and the aggregate production function". Review of Economics and Statistics, 39, 312-320.

Solow,R.M.(1987). Growth Theory, an exposition, Oxford University Press.

Swan,T.W.(1956). "Economic growth and capital accumulation". Economic Record 32, 334-361.

Temple, J.R.W.(1999a). "The new growth evidence”. Journal of Economic Literature, 37 (1), 112-156.

Temple, J.R.W.(1999b). “A positive effect of human capital on growth”. Economics Letters, 65(1), 131-134.

Temple, J.R.W.(2001). “Generalizations that aren't: Evidence on education and growth ". European Economic Review, 45(4-6), 905-918.

World Bank(1996). World Development Report. New York: Oxford 